\title{
Correction to: Numerical solution and convergence analysis of steam injection in heavy oil reservoirs
}

\author{
H. Hajinezhad ${ }^{1}$ - Ali R. Soheili ${ }^{1}$ Mohammad R. Rasaei ${ }^{2}$ - F. Toutounian ${ }^{1}$
}

Published online: 15 September 2018

(C) Springer Nature Switzerland AG 2018

\section{Correction to: Comput Geosci}

https://doi.org/10.1007/s10596-018-9763-3

The original publication of this manuscript which appeared online last 10 August, 2018 contains errors. There were several mistakes that appeared in the text body, Algorithms 1 and 2, Fig. 1 and Equation 16 introduced during typesetting process. The Publisher apologizes for these errors.

The original article has been corrected.

The online version of the original article can be found at https://doi.org/10.1007/s10596-018-9763-3.

Ali R. Soheili

Soheili@um.ac.ir

1 Department of Applied Mathematics, Faculty of Mathematical Sciences, Ferdowsi University of Mashhad, Mashhad, Iran

2 Institute of Petroleum Engineering, College of Engineering, Tehran University, Tehran, Iran 